\title{
Elastic and plastic deformations in a high entropy alloy investigated using a nanoindentation method
}

\author{
D. Wu ${ }^{\mathrm{a}^{*}}$, J.S.C. Jang ${ }^{\mathrm{b}}$, T.G. Nieh ${ }^{\mathrm{a}}$ \\ ${ }^{a}$ Department of Materials Science and Engineering, University of Tennessee, Knoxville, TN \\ 37996, USA \\ ${ }^{\mathrm{b}}$ Institute of Materials Science and Engineering; Department of Mechanical Engineering, \\ National Central University, Chung-Li 32001, Taiwan, ROC \\ * Please send all correspondence to Dr. D. Wu (Email: dwu10@vols.utk.edu)
}

\begin{abstract}
We employed instrumented indentation technique to study the elastic and plastic deformations in a face-centered cubic (fcc) high-entropy alloy NiFeCoCrMn. Single-crystal Ni was also examined for direct comparison. Tests were carried out using indenters with different tip radii to investigate the effect of indented volume on deformation processes. It was found that when the tip radius increased, the shear stress required for the occurrence of indentation pop-in decreased, which was attributable to a higher probability to find dislocations under a larger tip radius. We proposed a statistical model to describe the results quantitatively. In the plastic region, $\mathrm{NiFeCoCrMn}$ was much stronger than $\mathrm{Ni}$, presumably resulted from a large lattice distortion in the multicomponent $\mathrm{NiFeCoCrMn}$ alloy. We found that the response of both materials at large indentation depth could be described by the classical Nix-Gao model, but when the indentation depth was shallow, the indenter tip must be treated as a sphere and Swadener's model offered a better description. In any event, it was necessary to introduce a scaling factor $f$ to describe the effective stressed volume underneath the indenter tip to compensate for the overestimated hardness values. A map of indentation pressure against dislocation density was also summarized in this study.
\end{abstract}


Keywords: A. high-entropy alloys; B. incipient plasticity; B. indentation size effect; B. dislocation dynamics; F. nanoindentation

\section{Introduction}

High entropy alloys (HEAs) have received large attention from the materials science community due to their extraordinary properties [1] since they were introduced about a decade ago [2]. HEAs are multicomponent alloys containing several components (often 5) in equal atomic proportions. This new class of alloys is, in principle, expected to exhibit a large degree of mutual solubility in a single-phase structure, instead of complex ordered intermetallics, as a result of having high configurational entropy. However, the majority of HEAs is actually multiphase [3-12], suggesting a high entropy, sometimes, is not a guarantee for the formation of simple solid-solution phase, and the competition between entropy and enthalpy eventually determines the final phase formation.

There are, in fact, only a few HEAs with a true single-phase face-centered cubic (fcc) [13,14], body-centered cubic (bcc) [15-18] or hexagonal close-packed (hcp) [19] structure, in which the high-entropy effect dominates. Among them, the equiatomic fcc-NiFeCoCrMn alloy [13] is a prominent example that exhibits high phase stability, and its mechanical properties and microstructure have been studied [20-26]. For instance, Otto et al [23] reported that both yield strength, $\sigma_{\mathrm{y}}$, and tensile strength, $\sigma_{\mathrm{UTS}}$, of this HEA increased with decreasing temperature, and the temperature dependence of $\sigma_{\text {UTS }}$ was determined by deformation twins at low temperature, but the temperature dependence of $\sigma_{\mathrm{y}}$ was from a solid-solution effect. Wu et al $[27,28]$ further investigated the effect of temperature on the mechanical strength of this fcc-NiFeCoCrMn 
system, and found that each constituent elements produced different strengthening effects on the alloys, and the effect of temperature depends on the number and the types of constituents.

Recently, studies on the elastic-plastic deformation behavior of HEAs using micromechanical tests, e.g., micropillar compression [15] and nanoindentation [26], also began to emerge. These micro-mechanical tests have major advantage of revealing the intrinsic properties of a material with a minimum possible influence from 2-dimensional microstructural defects (e.g., grain boundary, twin boundary). Zou et al [15] conducted compression on highentropy alloy NbMoTaW micropillars and observed a higher compression strength in the alloy pillar as compared to pure $\mathrm{Nb}$, Mo, Ta, and $\mathrm{W}$ pillars, indicating homogeneous intermixing of constituent elements can produce strong lattice friction in the multicomponent HEA. They also observed the strength of bcc HEA micro-pillar is about 3 times higher than that of their bulk counterparts, suggesting some kind of sample size effect.

The elastic-plastic deformation behavior of HEAs has also been characterized by nanoindentation technique. For example, Zhu et al [26] studied indentation pop-ins and determined the critical shear stress for the incipient plasticity in the fcc-NiFeCoCrMn alloy. Their results indicated that plastic yielding of the NiFeCoCrMn alloy is different from that of the pure metals. Other papers $[29,30]$ also reported that yield strength of pure metals (e.g., Mo, Ni, Cr) depends on the tip radius of the indenter, and specifically the smaller is the tip radius, the higher is the yield strength.

In this study, the elastic/plastic deformation of a high entropy alloy NiFeCoCrMn is studied using instrumented indentation technique and directly compared with that of a nickel 
single crystal. The indented volume was regulated by the applied load and the radius of the indenter tip, and its effect on the deformation behavior of the HEA was evaluated.

\section{Materials and methods}

Samples with the nominal composition of NiFeCoCrMn (in atomic proportion) were prepared by arc-melting a mixture of the constituent elements (purity $>99 \mathrm{wt} \%$ ) in a Ti-gettered high-purity argon atmosphere. The alloy ingots were remelted four times in high-purity argon atmosphere to ensure their homogeneity. In the last melting, the liquid melt was suction-cast into a water-cooled rectangular $\mathrm{Cu}$ mold with a dimension of $30 \mathrm{~mm} \mathrm{~W}$ x $60 \mathrm{~mm} \mathrm{~L}$ x $3 \mathrm{~mm} \mathrm{~T}$. The as-cast ingots were homogenized at $1200{ }^{\circ} \mathrm{C}$ for $4 \mathrm{~h}$, and then cold rolled to $50 \%$ reduction in thickness. Rectangular samples were sliced from the rolled plates, ground, and polished to a mirror finish. The polished samples were additionally annealed at $1000{ }^{\circ} \mathrm{C}$ in vacuum for $2 \mathrm{~h}$ to induce recrystallization and grain growth, and to remove residual surface stresses from the mechanical polishing. The microstructure of the annealed alloy was examined using optical microscopy and SEM, and the grain size was found in the range of $60 \sim 120 \mu \mathrm{m}$. XRD pattern has shown a single phase fcc-NiFeCoCrMn alloy with the lattice parameter of about $3.594 \AA$. For comparison, a nickel single crystal was also tested. The single-crystal Ni(100) sample was prepared using a directional floating zone melting technique [31], and the test sample was ground and electropolished in an electrolyte containing $40 \%$ sulfuric acid before the indentation tests.

Instrumented indentation tests were performed on samples at room temperature using a Hysitron Triboindenter (Hysitron Inc., Minneapolis, MN). Three diamond indenters (two Berkovich tips and a cube corner tip) were used to evaluate the elastic-plastic response, and the tip radii of these three tips were calibrated on single-crystal tungsten to be $80 \mathrm{~nm}$ (cube corner), 
$255 \mathrm{~nm}$ (Berkovich) and $759 \mathrm{~nm}$ (Berkovich). To avoid the overlap of the plastic zone underneath the indenter, indentation tests were conducted with a $6 \mu \mathrm{m}$ interval with a maximum load of $200 \mu \mathrm{N}$ for tips $\mathrm{R}=80,255 \mathrm{~nm}$ and $1000 \mu \mathrm{N}$ for the tip $\mathrm{R}=759 \mathrm{~nm}$. At least 70 indents were made for each tip radius. During each indentation test, a constant loading rate of $400 \mu \mathrm{N} / \mathrm{s}$ was imposed to eliminate loading rate effect, and the maximum load was held for $1 \mathrm{~s}$ before unloading. Indented sites are within the same grain and at least $6 \mu \mathrm{m}$ away from the grain boundary to avoid possible effects of orientation and grain boundary. To investigate the plastic behavior, indentation tests were also performed in a neighboring grain with a maximum load of $10 \mathrm{mN}$ and a $20 \mu \mathrm{m}$ interval. A Berkovich indenter $(\mathrm{R}=255 \mathrm{~nm})$ was used, and its area function was calibrated with fused silica.

An atomic force microscope MFP-3D ${ }^{\mathrm{TM}}$ (Asylum Research Inc, Santa Barbara, CA) was utilized under the air image mode to evaluate the sample surface before and after indentation tests. The probe (AC160TS-R3) used for imaging has a tip radius of about $9 \pm 2 \mathrm{~nm}$. Both the annealed $\mathrm{NiFeCoCrMn}$ and single-crystal $\mathrm{Ni}$ have an rms roughness value of about $2 \mathrm{~nm}$.

\section{Results}

\subsection{Elastic response of $\mathrm{NiFeCoCrMn}$}

In an indentation test, the transition from elasticity to plasticity is marked by the first popin on the load-displacement curves, as shown in Figure 1a and 1b, for NiFeCoCrMn and singlecrystal $\mathrm{Ni}$, respectively. In the figures, three different tip radii are used and it is evident that the larger is the tip radius, the higher is the load to reach a given penetration depth for the occurrence of pop-in. The residual indented marks from the indenters $(R=80$ and $759 \mathrm{~nm})$ were examined 
by AFM, as shown in Figure 2. It is noted that the pyramidal indenter actually exhibits a spherical bottom with a curvature that is consistent with the calibrated tip radii.
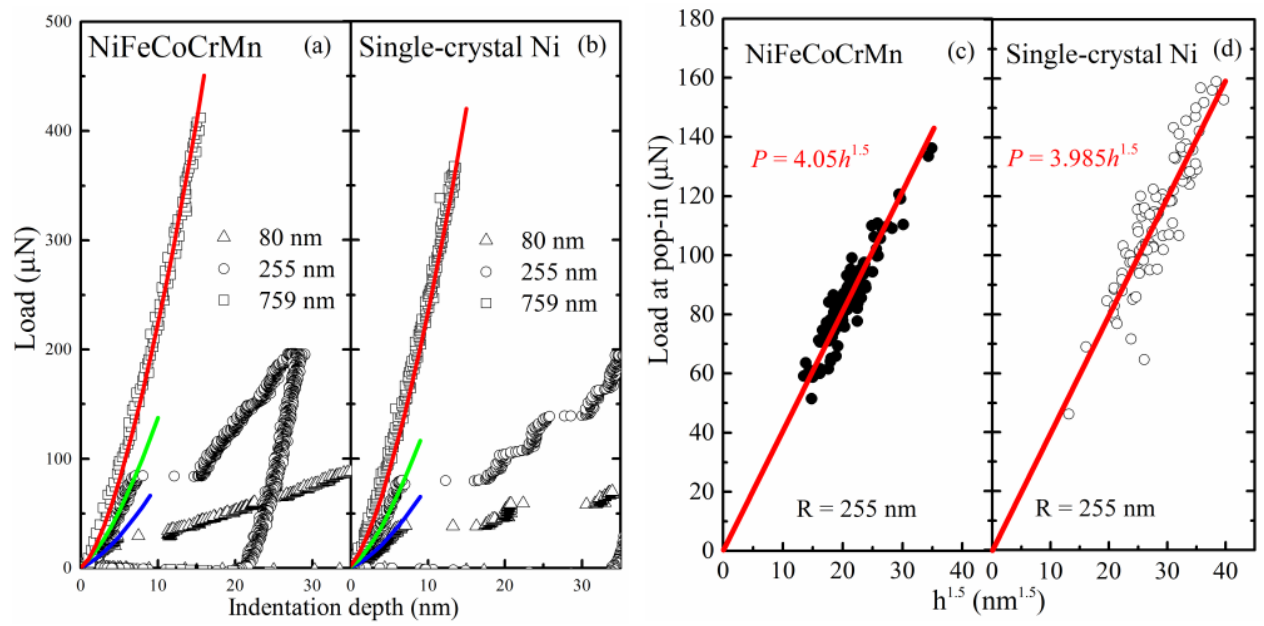

Figure 1 Typical load-displacement curves from the nanoindentation tests on the annealed $\mathrm{NiFeCoCrMn} \mathrm{(a)} \mathrm{and} \mathrm{single-crystal} \mathrm{Ni}$ (b) using indenters with three tip radii $(\mathrm{R}=80,255,759$ $\mathrm{nm}$ ), respectively. The elastic part of the loading curves can be well described by the Hertzian relation. The reduced elastic moduli of $190.21 \pm 1.22$ and $187.18 \pm 1.59 \mathrm{GPa}$ were calculated from the slopes of $\mathrm{P}-\mathrm{h}^{1.5}$ plot at pop-in for $\mathrm{NiFeCoCrMn}$ (c) and single-crystal $\mathrm{Ni}$ (d), respectively.
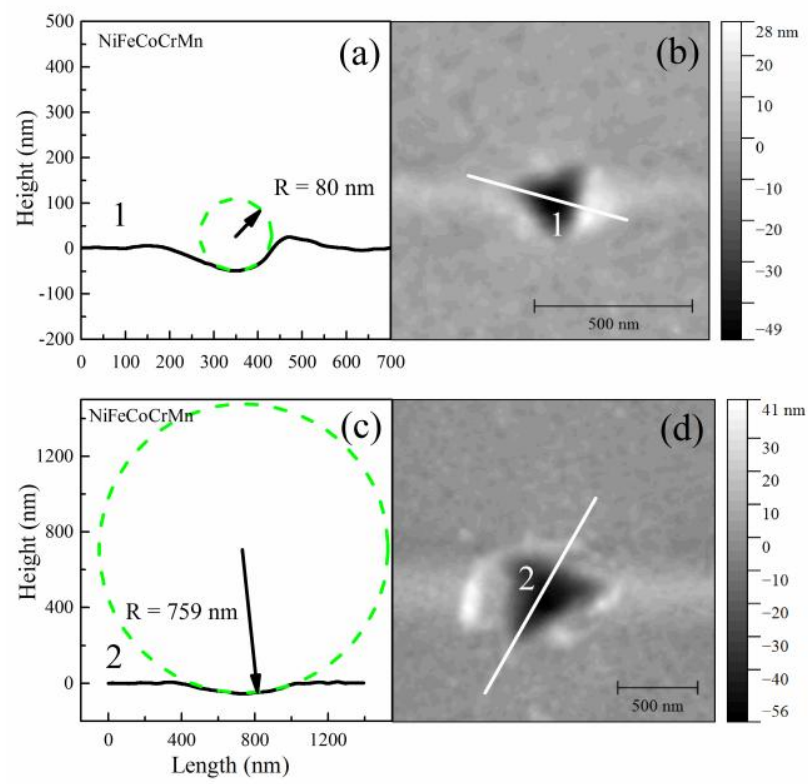

Figure 2 The blunt bottom of the indent profiles (a) and (c), which are extracted from the AFM topographic images of residual impressions on $\mathrm{NiFeCoCrMn} \mathrm{(b)} \mathrm{and} \mathrm{(d),} \mathrm{agree} \mathrm{well} \mathrm{with} \mathrm{the} \mathrm{tip}$ radii $R=80$ and $759 \mathrm{~nm}$, respectively. 
The elastic part of the loading curve prior to a pop-in event is described by the Hertzian relation,

$$
P=\frac{4}{3} E_{r} \sqrt{R h^{3}}
$$

where $R$ is the tip radius of the indenter, $h$ is the indentation depth, $E_{r}=\left[\left(1-v_{\text {in }}{ }^{2}\right) / E_{i n}+\left(1-v_{\mathrm{s}}{ }^{2}\right) / E_{s}\right]^{-1}$ is the reduced elastic modulus of the tested sample, $\left(v_{\mathrm{in}}, E_{i n}\right)$ and $\left(v_{\mathrm{s}}, E_{s}\right)$ are the Poisson's ratio and elastic modulus of the indenter and sample, respectively. Data of $\mathrm{P}-\mathrm{h}^{1.5}$ pairs at pop-ins obtained from NiFeCoCrMn and Ni single crystal under the indenter $(\mathrm{R}=255 \mathrm{~nm})$ are plotted in Figure 1c and 1d. The reduced elastic moduli for NiFeCoCrMn and $\mathrm{Ni}$ are calculated to be $190.21 \pm 1.22$ and $187.18 \pm 1.59 \mathrm{GPa}$, respectively. Using these $E_{\mathrm{r}}$ values, the elastic loading curves for other tip radii $\mathrm{R}=80$ and $759 \mathrm{~nm}$ are found to agree with the Hertzian relation. Using the mechanical parameters for the diamond indenter $\left(v_{\text {in }}=0.07, E_{\text {in }}=1141 \mathrm{GPa}\right)[32]$ and samples $\left(v_{\mathrm{HEA}}=0.26, v_{\mathrm{Ni}}=0.31\right)[28]$, the elastic moduli of $\mathrm{NiFeCoCrMn}$ and $\mathrm{Ni}$ are deduced as 212.62 and 202.2 GPa, respectively. The fact that the NiFeCoCrMn alloy has a higher elastic modulus but a larger lattice parameter than $\mathrm{Ni}(0.359 \mathrm{~nm}$ for $\mathrm{NiFeCoCrMn}$ and $0.352 \mathrm{~nm}$ for $\mathrm{Ni})$ suggests a stronger bond in the alloy.

\subsection{Plastic response of $\mathrm{NiFeCoCrMn}$}



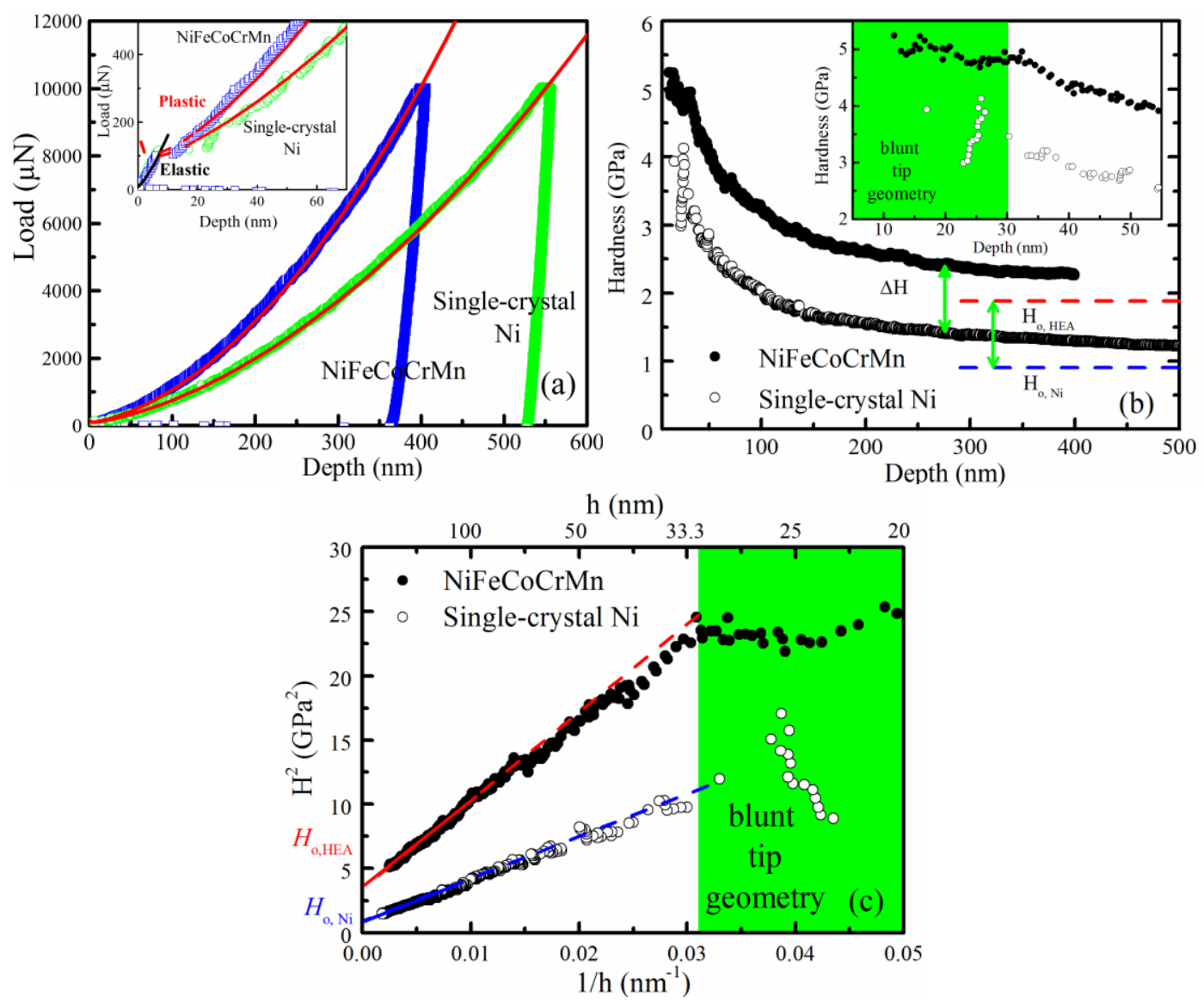

Figure 3 Typical load-displacement curves (a) produced from the Berkovich indenter $(R=255$ $\mathrm{nm}$ ) on single-crystal $\mathrm{Ni}$ and $\mathrm{NiFeCoCrMn}$. A hardening effect $\Delta \mathrm{H}$ in $\mathrm{NiFeCoCrMn}$ with respect to $\mathrm{Ni}$ was observed from the plotting of hardness $\mathrm{H}$ against indentation depth $\mathrm{h}(\mathrm{b})$. This term was incorporated in the Nix-Gao model (Eq. (S2)) to provide a good prediction (red solid line) of the load-displacement curves. A major breakdown of the linear relation $\mathrm{H}^{2}$ vs $1 / h$ (c) when $\mathrm{h}<$ $30 \mathrm{~nm}$ probably results from the spherical tip geometry of indenter 

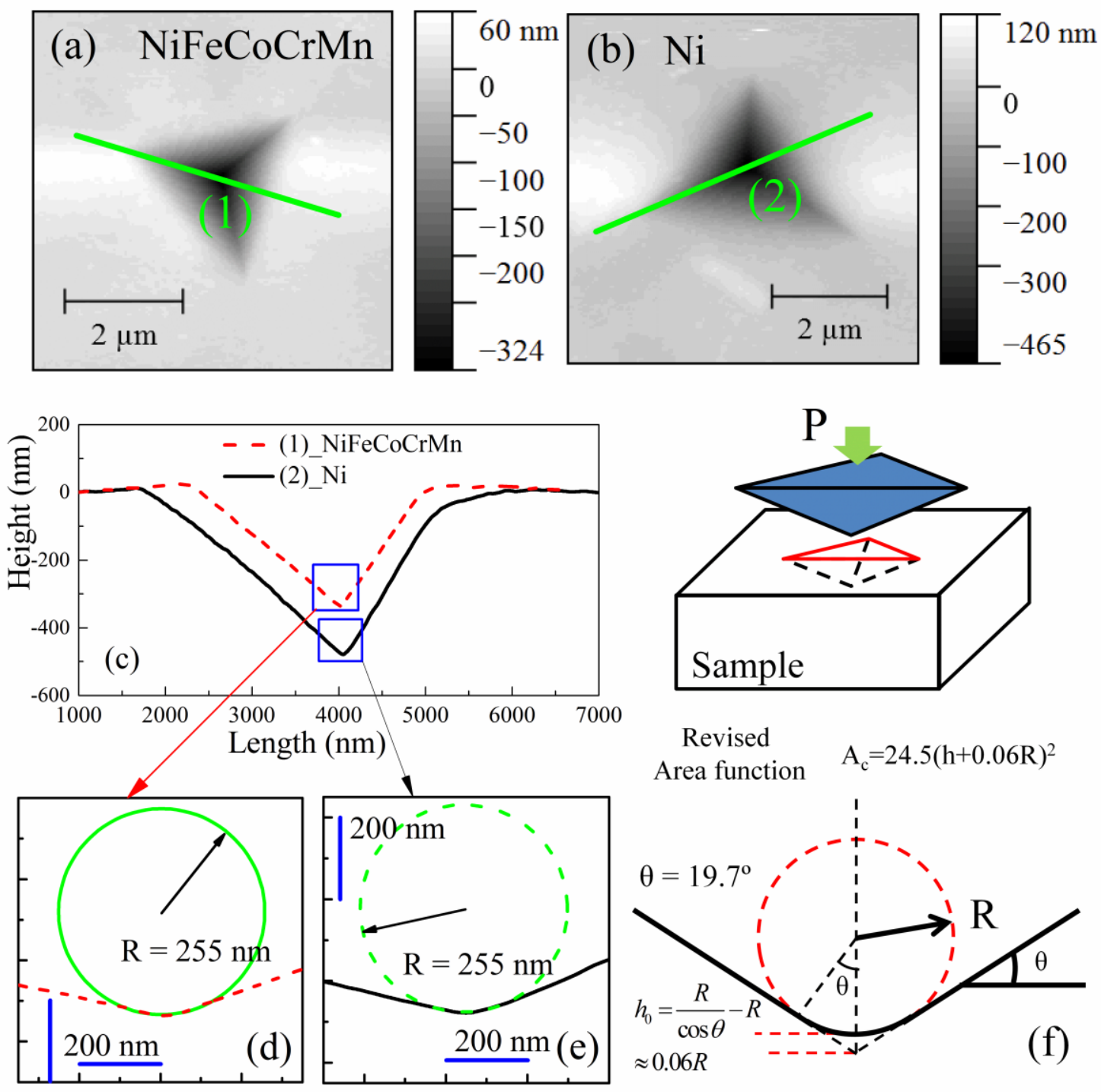

Figure 4 AFM topographic images of typical indents on $\mathrm{NiFeCoCrMn} \mathrm{(a)} \mathrm{and} \mathrm{single-crystal} \mathrm{Ni}$ (b) using the Berkovich tip $(\mathrm{R}=255 \mathrm{~nm})$ at a maximum load of $10 \mathrm{mN}$, and the general shape (c) and blunt tip geometry (d), (e) of the Berkovich indenter shown by the extracted 2-D profiles. A modified area function of the Berkovich indenter $A_{c}=24.5(h+0.06 R)^{2}$ is then proposed (f).

Load-displacement curves from indentation tests of $\mathrm{NiFeCoCrMn}$ and single crystal $\mathrm{Ni}$ at a high load of $10 \mathrm{mN}$ are shown in Figure 3a. A shallower indentation depth indicates the HEA is harder than Ni. In Figure 3b, hardness values of these two materials are plotted against the indentation depth, $h$. Both curves exhibit similar trend and the HEA is harder than pure Ni, i.e., 


$$
\mathrm{H}_{\mathrm{HEA}}=\mathrm{H}_{\mathrm{Ni}}+\Delta \mathrm{H}
$$

Hardness is also noted to decrease with increasing $h$, revealing an indentation size effect (ISE) in both materials. Similar observation has been made in several crystalline materials [33,34], and Nix and Gao [35] proposed the dependence of the hardness $H$ on depth $h$ as:

$$
H^{2}=H_{o}^{2}\left(1+h^{*} / h\right)
$$

where $H_{\mathrm{o}}$ corresponds to the hardness at infinite depth, and $h^{*}$ is the characteristic length that depends on the indenter shape. The linear relation between $H^{2}$ and $1 / h$ appears to apply well in the micro-indentation scale, whilst significant deviation from the theory occurs when the indentation depth is below $100 \mathrm{~nm}[36,37]$. The breakdown of self-similar indenter geometry and incorrect size of plastic zone have been suggested to be the main causes of such deviation [38]. In fact, AFM tomographic images (Figure 4) of the residual impressions clearly demonstrate the current Berkovich indenter has a blunt tip. The 3-sided pyramid (Figure 4c) exhibits a spherical tip (Figure $4 \mathrm{~d}$ and $4 \mathrm{e}$ ) and the tip curvature agrees with the calibrated tip radius $\mathrm{R}=255 \mathrm{~nm}$. Consequently, the area function of a blunt Berkovich indenter is modified as $A_{\mathrm{c}}=24.5(h+0.06 R)^{2}$, as indicated in Figure 4f. It is apparent that, in Figure 3c, the predicted $H^{2}$ value begins to deviate from experimental data when $h$ is less than $50 \sim 75 \mathrm{~nm}$, and becomes appreciable when the depth is about $30 \mathrm{~nm}$. It is particularly noted that whereas self-similar indenter geometry is obeyed at large indentation depth, a blunt spherical shape profile should experimentally be found at the bottom of the indent. As shown in Figure 3c, data fit well at $h>100 \mathrm{~nm}$ according to the NixGao model (Eq. (3)), and the depth-independent hardness $H_{o}$ is extrapolated from the intercept of the fitting, as listed in Table 1. Evidently, the classic Nix-Gao model is useful even in the micrometer range. However, it is necessary to modify the model in order to describe very shallow depth, and it is presented in the following discussion sections. 
Table 1 Parameters in the Nix-Gao model for the indentation size effect in Ni single crystal and high-entropy alloy $\mathrm{NiFeCoCrMn}$

\begin{tabular}{ccccc}
\hline Materials & $\mathrm{E}_{\mathrm{r}}(\mathrm{GPa})$ & $\mathrm{H}_{0}(\mathrm{GPa})$ & $3 \sigma_{f}(\mathrm{GPa})$ & $f$ \\
\hline NiFeCoCrMn & $190.21 \pm 1.22$ & $1.88 \pm 0.08$ & $1.56[23]$ & 2.45 \\
$\mathrm{Ni}$ & $187.18 \pm 1.59$ & $0.90 \pm 0.04$ & $1.02[28]$ & 2.35 \\
\hline
\end{tabular}

According to the Nix-Gao model, $H_{\mathrm{o}}$ is the resistance to plastic flow in a material independent of the indenter geometry. Since the lattice frictions in pure fcc metals are usually negligible [39], $H_{\mathrm{o}}$ or resistance to plastic flow arises from the statistically stored dislocations (SSDs). According to Taylor's relation, the density of SSDs in the single crystal Ni can be estimated by the equation:

$$
H_{o, N i}=C \sigma_{f}=C M \alpha G b \sqrt{\rho_{S S D}}
$$

where $\mathrm{C}=3$ is the Tabor's factor, $M$ is the Taylor factor, 3.06 for fcc metals, $\alpha=0.5$ is applied for the complex stress field underneath the indenter, $G$ is the elastic shear modulus, $76 \mathrm{GPa}$ for $\mathrm{Ni}, b$ is the Burgers vector, $0.249 \mathrm{~nm}$ for $\mathrm{Ni}$. The value of $\rho_{\mathrm{SSD}}$ is, thus, estimated to be about $1.065 \times 10^{14} \mathrm{~m}^{-2}$, which is one order higher than $\rho_{\mathrm{SSD}}=1 \times 10^{13} \mathrm{~m}^{-2}$ reported in a fully annealed aluminum [40].

Under indentation, $\chi=\tan \theta / a$ is defined as a measure of the strain gradient underneath the indenter [35]. When $a \rightarrow \infty$, corresponding to infinite indentation depth, the strain gradient goes to zero at a fixed indenter angle $\theta$. Under this circumstance, the strain $\varepsilon$ is fixed and only depends on the indenter geometry. Since $\mathrm{Ni}$ and $\mathrm{NiFeCoCrMn}$ alloy have the same fcc structure and similar Burgers vector $(0.249 \mathrm{~nm}$ vs $0.254 \mathrm{~nm})$, the same strain $\varepsilon$ at the infinite indentation depth essentially would give the same $\rho_{\text {SSD }}$ value in these two materials. However, NiFeCoCrMn has a much higher $H_{\mathrm{o}}$ value than $\mathrm{Ni}\left(H_{\mathrm{o}}, \mathrm{HEA}=1.88 \mathrm{GPa}, H_{\mathrm{o}}, \mathrm{Ni}=0.9 \mathrm{GPa}\right)$ and the hardening term is 
$\Delta H=H_{\mathrm{o}, \mathrm{HEA}}-H_{\mathrm{o}, \mathrm{Ni}}=0.98 \mathrm{GPa}$. The hardness values of the two materials are consistent with the classical Tabor relation, namely, $H=3 \sigma_{f}$, where $\sigma_{f}$ is the flow strength [23,28].

This strengthening difference has been ascribed to be solid solution hardening before [2], but, in principle, the solid solution hardening refers to the strengthening locally distorted solvent lattice by the individual solute atoms. In HEAs, each element contributes equally to the composition, and the lattice is universally distorted, therefore, no element can be treated as solvent or solute. In such a case, the higher strength of NiFeCoCrMn compared to $\mathrm{Ni}$ is probably resulted from a higher lattice friction stress for dislocation motion in the distorted lattice of NiFeCoCrMn [41].

Use the value of $\rho_{\mathrm{SSD}}$ and $\Delta H$ for each material, the load-displacement responses can be well modeled by $P=\left(\Delta H+C M \alpha G b \sqrt{\rho_{S S D}+\rho_{G N D}}\right) A_{c}$ (Eq. (S2) in the supplementary material) and are shown as solid lines in Figure 3a. A scaling factor $f$ is introduced in the term for the density of geometrical necessary dislocation $\rho_{G N D}=\frac{3 \tan ^{2} \theta}{2 f^{3} b h}[42,43]$ to describe the effective size of plastic zone with respect to the contact radius. In the modeling, this factor is about 2.4 for both the HEA and Ni. It should be noted that this analytical model only describes the loaddisplacement curves at large indentation depth $(\mathrm{h}>25 \mathrm{~nm})$ as a result of inadequate area function. A more accurate description for shallow indentation will be discussed in the sections below.

\section{Discussion}

\subsection{Statistical analysis of the incipient plasticity of NiFeCoCrMn}

In general, a pop-in event is triggered when the maximum shear stress $\tau_{\max }$ underneath the indenter exceeds a critical value. The event usually consists of the nucleation and subsequent 
propagation of dislocations. According to contact mechanics, $\tau_{\max }$ occurs at about half of the contact radius $a$ underneath the indenter and is given by [44]

$$
\tau_{\max }=0.47 p_{m}=0.47 \frac{P}{\pi R h}
$$

where $p_{m}$ is the mean pressure beneath the indenter, $P$ is the applied load. For a spherical tip, the contact area is $\pi a^{2}$, where $a=\sqrt{R h}$ is the contact radius.
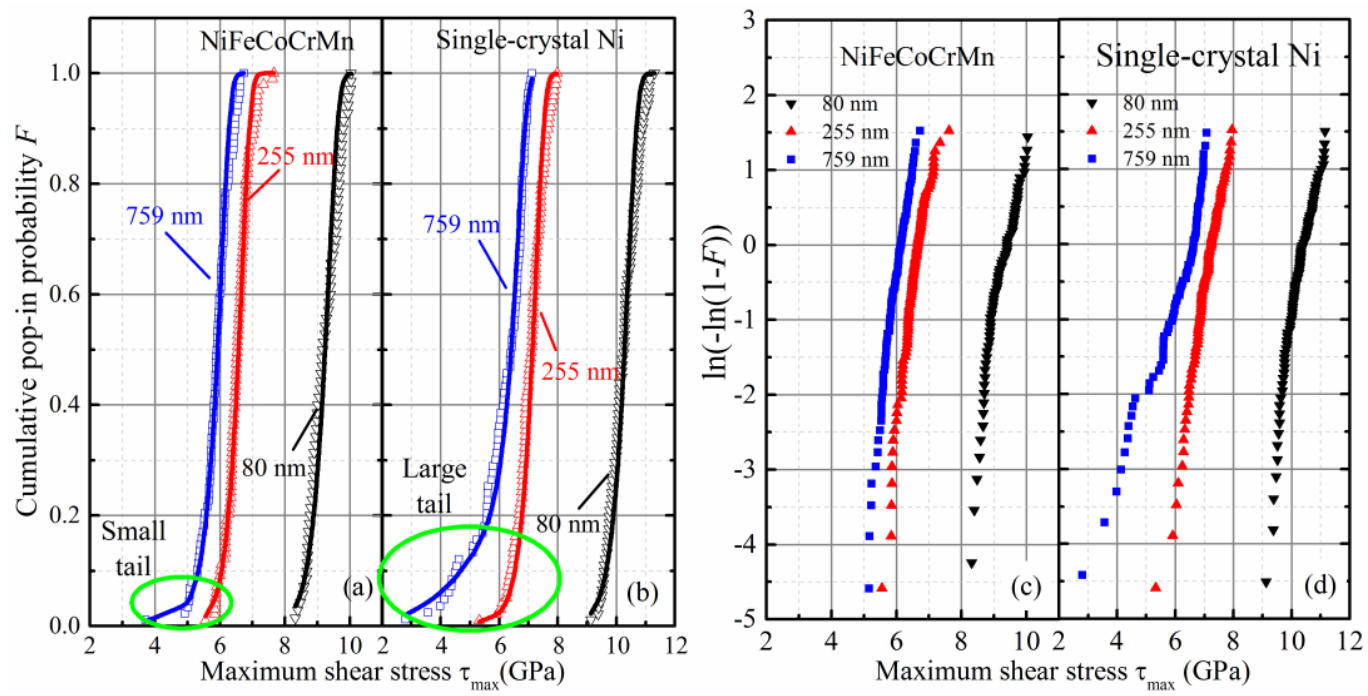

Figure 5 The cumulative pop-in probability $F$ underneath the indenters on $\mathrm{NiFeCoCrMn} \mathrm{(a)} \mathrm{and}$ single-crystal $\mathrm{Ni}$ (b). Solid lines are predictions based on a model combining dislocation nucleation process and the activation process of pre-existing dislocation (Eq. (10)). The activation volume for dislocation nucleation is deduced from the slope of the plot of $\ln [-\ln (1-F)]$ against $\tau_{\max }$ underneath indenters with the tip radius $R=80 \mathrm{~nm}$ for $\mathrm{NiFeCoCrMn}$ (c) and singlecrystal Ni (d).

To study effect of the indenter tip size, we carried out pop-in experiments using indenters with different tip radii. The maximum shear stresses for the occurrence of pop-in in $\mathrm{NiFeCoCrMn}$ and $\mathrm{Ni}$ single crystal are calculated under different indenter tips, and the cumulative probability of pop-in $F$ for each tip radius is plotted against $\tau_{\max }$ in Figure $5 \mathrm{a}$ and $5 \mathrm{~b}$. 
It is noted that, in both $\mathrm{NiFeCoCrMn}$ and pure $\mathrm{Ni}$, the maximum shear stress ranges from $4 \mathrm{GPa}$ to $10 \mathrm{GPa}$, which is in the proximity of the theoretical strength for each material [31] (G/30 G/5, where $G$ is the elastic shear modulus of the material, $80 \mathrm{GPa}$ for NiFeCoCrMn [28] and $76 \mathrm{GPa}$ for $\mathrm{Ni}$ ). As the tip radius increases, the $\tau_{\max }$ value decreases and a tail begins to develop in the low-stress end on the cumulative probability function $F$ (encircled in green). This tailing phenomenon has also been previously observed in $\mathrm{Cr}$ [29] and Mo [30,45], and is attributable to a transition of mechanism from dislocation nucleation in a dislocation-free material to dislocation activation in a material containing dislocations when the tip radius increases.

When applying a small indenter tip, there is a high probability to probe a region within which dislocation is absent and the shear stress for the pop-in is close to the theoretical strength for the nucleation of new dislocations in the material. The dislocation nucleation process has been proposed as a shear-biased event and the nucleation rate in a unit volume of material under a shear stress $\tau$ [46] can be written as

$$
\dot{N}=N_{o} \exp \left(-\frac{\varepsilon-\tau v}{k T}\right)
$$

where $N_{\mathrm{o}}$ is the pre-exponential attempt frequency, $\varepsilon$ is the energy barrier for dislocation nucleation, and $v$ is the activation volume. Assume $F$ is the cumulative probability for pop-ins, then, $(1-F)$ is the population of indentations in which the pop-in event has not yet occurred, and the rate of change in $F$ can be described by the following equation:

$$
\dot{F}=(1-F) \dot{N}
$$

Insert Eq. (6) into Eq. (7), and take an integration over the highly stressed volume underneath the indenter (scales with the contact radius, $\Omega \sim \pi a^{3}$ ), the cumulative probability for nucleation 
events within the sampling volume can be written as a function of the maximum shear stress $\tau_{\max }$ for pop-in [46]:

$$
F_{\text {nucleation }}\left(\tau_{\max }\right)=1-\exp \left[-\frac{9 \pi R \eta}{4 E_{r} \dot{P} \alpha^{6}} \gamma\left(\tau_{\max }\right)\right]
$$

where $\dot{P}$ is the indentation loading rate, the parameter $\eta=\mathrm{N}_{0} \exp (-\varepsilon / \mathrm{kT})$ indicates the rate at which defects nucleate in an unstressed crystal due to thermal activation alone, $\chi\left(\tau_{\max }\right)$ is a complex function of $\tau_{\max }$, and the parameter $\alpha$ is a collection of time-independent terms given by $\alpha=\frac{0.47}{\pi}\left(\frac{4 E_{r}}{3 R}\right)^{\frac{2}{3}} \frac{v}{k T}$. Eq. (8) is noted for a crystal that does not contain a dislocation and the shear stress for the pop-in is near the theoretical strength of the crystal.

However, when a large indenter tip radius is applied, there is a higher probability to find pre-existing defects in the plastic zone underneath the indenter, and pop-in can be triggered from one of these defects (e.g. Frank-Read sources) at a relatively low shear stress $\tau_{\text {pop-in }}$. Assuming the defect distribution follows Poisson's statistics, Morris et al [30] have shown that the probability for the absence of pop-in in the highly stressed zone is $\exp \left[-\rho_{\text {defect }} V\left(\tau>\tau_{\text {pop-in }}\right)\right]$, where $\rho_{\text {defect }}$ is the density of pre-existing defects, $V$ is the high-stressed volume where the local stress $\tau>\tau_{\text {pop-in }}$, and $\tau_{\text {pop-in }}$ is the critical shear stress to activate the source at the pre-existing defects. The cumulative probability for pop-in arising from the activation of pre-existing defects is, then,

$$
F_{\text {activation }}=1-\exp \left[-\rho_{\text {defect }} V\left(\tau>\tau_{\text {pop-in }}\right)\right]
$$


In general, while indenting a material, both of the above two situations should be considered. In such a case, the probability for the absence of pop-in is $\exp \left(-\rho_{\text {defect }} V\right) \exp \left[-\frac{9 \pi R \eta}{4 E_{r} \dot{P} \alpha^{6}} \gamma\left(\tau_{\max }\right)\right]$, and the resultant cumulative probability for pop-in is

$$
F_{\text {total }}=1-\exp \left[-\rho_{\text {defect }} V-\frac{9 \pi R \eta}{4 E_{r} \dot{P} \alpha^{6}} \gamma\left(\tau_{\text {max }}\right)\right]
$$

Table 2 Parameters used for modeling the cumulative probability of pop-in $F$ in NiFeCoCrMn and $\mathrm{Ni}$ single crystal

\begin{tabular}{cccc}
\hline Materials & $v\left(\mathrm{~b}^{3}\right)$ & $\eta\left(\times 10^{13} \mathrm{~s}^{-1} \mathrm{~m}^{-3}\right)$ & $\rho_{\text {defect }}\left(\mathrm{m}^{-3}\right)$ \\
\hline NiFeCoCrMn & 0.65 & $9.92 \sim 93.2$ & $4 \times 10^{16}$ \\
$\mathrm{Ni}$ & 0.69 & $2.15 \sim 84.9$ & $2.3 \times 10^{17}$ \\
\hline
\end{tabular}

Mathematically, we can rewrite Eq. (8) into a double logarithmic form as $\ln [-\ln (1-F)]=v \tau_{\max } / k T+\beta\left(\tau_{\max }\right)$, where $\beta\left(\tau_{\max }\right)$ in the equation is a weak function of $\tau_{\max }$ as compared with the first term, one can deduce the activation volume $v$ from the slope of the linear fitting of $\ln [-\ln (1-F)]$ against $\tau_{\max }$. In Figure $5 \mathrm{c}$ and $5 \mathrm{~d}$, the pop-in data for NiFeCoCrMn and $\mathrm{Ni}$ are plotted in such form and the activation volume is determined to be around $0.7 b^{3}$, as listed in Table 2. To minimize data variation caused by pre-existing defects, data obtained from the sharpest indenter $(R=80 \mathrm{~nm})$ are particularly used to evaluate the activation volume.

The cumulative probability of pop-in $F$ for NiFeCoCrMn and Ni under different tips is fitted using Eq. (10) and the results are shown in Figure 5. In the fitting, $\tau_{\text {pop-in was taken to be } 38}$ $\mathrm{MPa}(\sim \mathrm{G} / 2000)$, which is close to the resolved shear stress in $\mathrm{Ni}(\sim 28 \mathrm{MPa})[47,48]$, and the activation of slip systems in Ni micropillars (40-60 MPa) [49]. The parameters for modeling are summarized in Table. 2. It is noted in the modeling that the density of pre-existing defects is set 
in the range of $10^{16} \sim 10^{17} \mathrm{~m}^{-3}$. Assuming dislocation lines are spaced in a cubic array, this defect density is equivalent to a dislocation density of about $10^{11} \mathrm{~m}^{-2}$, which is the typical value in a fully recrystallized crystal $[30,50]$.

\subsection{Plastic deformation of NiFeCoCrMn under spherical tip of indenters}

It has been pointed out that, when a blunt pyramidal indenter is used, it actually produces a spherical impression at an extremely shallow indentation depth $(h<R / 10)$. Swadener et al [51] has extended Nix and Gao's framework [35], and developed a model that describes the ISE under spherical indenters. In the model, the density of geometrically necessary dislocation beneath a spherical indenter is derived as $\rho_{\mathrm{GND}}=1 / b \mathrm{R}$, where $R$ is the radius of the spherical tip. Swadener's model generally agrees with the experimental results under larger spherical indenter ( $\mathrm{R}>10 \mu \mathrm{m}$ ), but overestimates the hardness when the depth is shallow under a smaller indenter. On the other hand, the traveling distance of the leading dislocation just after pop-in [52] was measured, and it could be regarded as the size of the plastic zone $(\sim 1 \mu \mathrm{m})$. This zone size was about twice the diameter of the residual indent impression, i.e., $2 \sqrt{2 R h-h^{2}} \sim 475 \mathrm{~nm}$. A scaling factor $f$ was subsequently introduced to correct the radius of plastic zone $a_{\mathrm{pz}}$, namely, $a_{\mathrm{pz}}=f a_{\mathrm{c}}$, where $a_{\mathrm{c}}$ is the contact radius $[42,53]$. In such a case, $\rho_{\mathrm{GND}}$ becomes $\rho_{G N D}=1 / f^{3} b R$ (refer to the supplementary material), and $P=k h$ (Eq. S3), where $k=2 \pi R\left(\Delta H+C M \alpha G b \sqrt{\rho_{S S D}+1 / f^{3} b R}\right)$ is constant for a given indenter with a tip radius of $R$. Insert the parameters $(R, b, \Delta H, G, \alpha$, and $\rho_{\mathrm{SSD}}$ ) into Eq. S3 we find that the load-displacement responses (Figure 6) agree well with this linear correlation [54]. The scaling factor $f$ used in the modeling ranges from 2.4 to 2.65 , as listed in Table 3. These results are close to 2.4 used previously in Figure 3 and also consistent with 
values reported in the literature [42,53]. It is noted that within data scatter, $f$ values for NiFeCoCrMn and Ni appear to be similar.
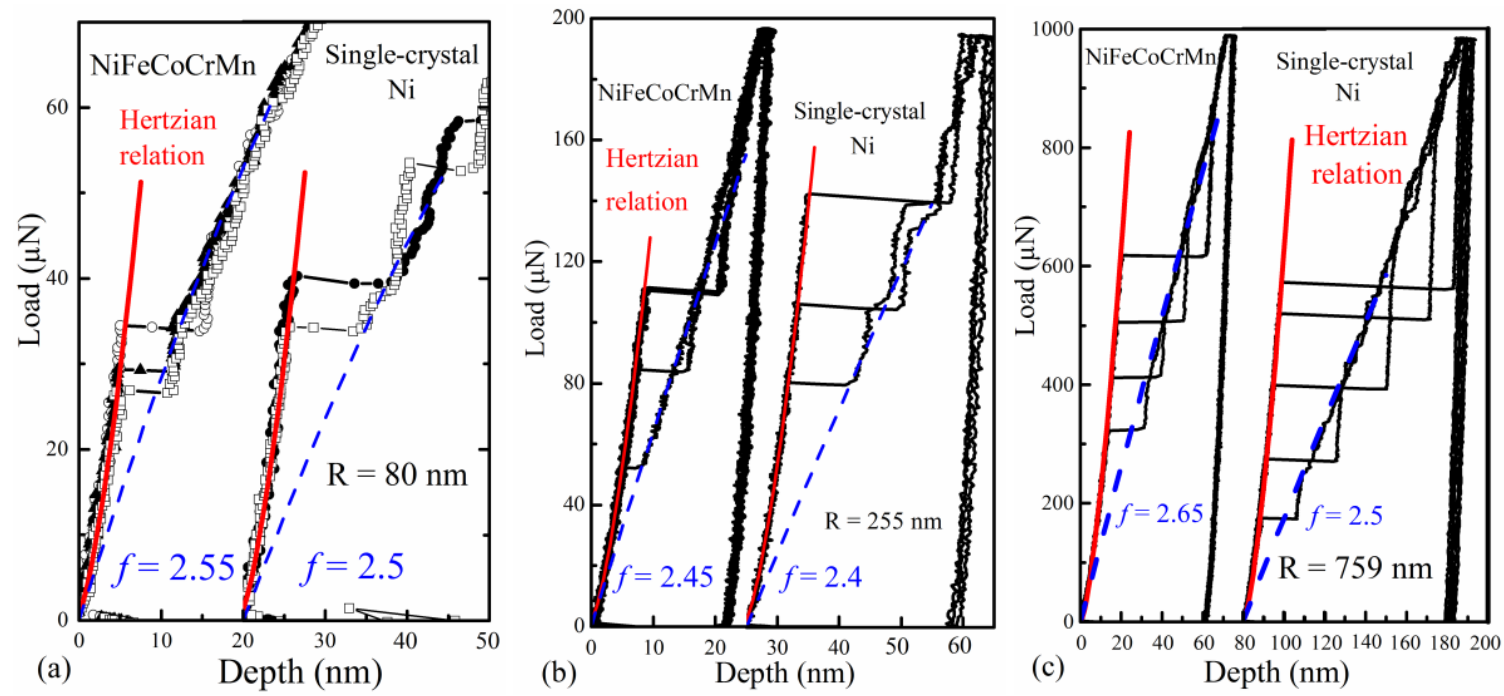

Figure 6 Load-displacement curves for the indentation tests on NiFeCoCrMn alloy and singlecrystal Ni using indenters $R=80$ (a), 255 (b), $759 \mathrm{~nm}$ (c), respectively. The red curves show the elastic response given by Hertzian theory, and the dotted blue curves show the plastic response predicted by Eq. (S3) under a spherical indenter tip.

Table 3 Plastic zone size factor $f$ used in the modeling of the plastic responses in nanoindentation

\begin{tabular}{cccc}
\hline Materials & $f(\mathrm{R}=80 \mathrm{~nm})$ & $f(\mathrm{R}=255 \mathrm{~nm})$ & $f(\mathrm{R}=759 \mathrm{~nm})$ \\
\hline NiFeCoCrMn & 2.55 & 2.45 & 2.65 \\
$\mathrm{Ni}$ & 2.5 & 2.4 & 2.5 \\
\hline
\end{tabular}

\section{3 Effect of tip radius on the mean pressure underneath the indenter}

In previous sections, the elastic and plastic deformations of $\mathrm{NiFeCoCrMn}$ alloy and $\mathrm{Ni}$ single crystal have been discussed and the pop-in event divides/connects these two deformation regions. In this section, we address the variation of mean pressure underneath the indenter 
before and after the pop-in event, and further evaluate the effects of alloying and tip radius on the strength of NiFeCoCrMn.
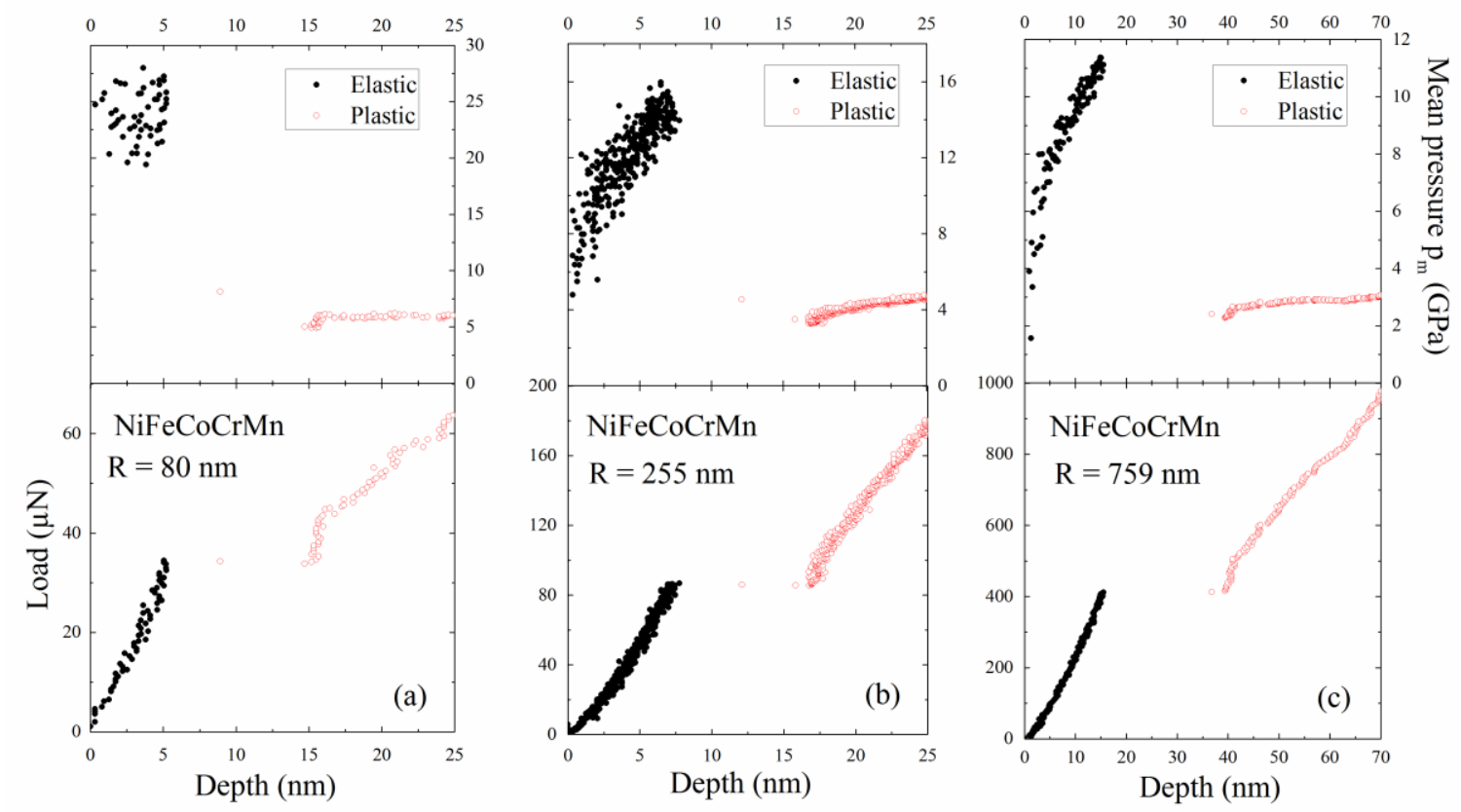

Figure 7 Mean pressure underneath the indenter before and after pop-in in NiFeCoCrMn at $R=$ $80 \mathrm{~nm}$ (a), $255 \mathrm{~nm}$ (b), $759 \mathrm{~nm}$ (c)

During indentation tests, the deformation resistance of the material can be evaluated from the mean pressure $p_{m}$ underneath the indenter, namely, the applied load over the projected contact area. Apply the contact radius $\sqrt{R h}$ and $\sqrt{2 R h-h^{2}}$ for the elastic loading prior to pop-in and plastic contact after pop-in (Figure $\mathrm{S} 3 \mathrm{~b}$ ), respectively, evolutions of mean pressure $p_{\mathrm{m}}$ throughout a pop-in event at different tip radii in $\mathrm{NiFeCoCrMn}$ are calculated and shown in Figure 7. It is noted that, in both samples and regardless of the tip radii, the mean pressure $p_{m}$ reaches a high value $(11 \sim 25 \mathrm{GPa})$ in the elastic loading stage, but sharply drops to a low value (3 $\sim 5 \mathrm{GPa})$ once the pop-in takes place. The high $p_{\mathrm{m}}$ value prior to the pop-in corresponds to a high shear stress required to nucleate (or activate) dislocation in the materials, while the low $p_{\mathrm{m}}$ 
value after the pop-in is the stress required to overcome the lattice friction and dislocation interactions for plastic flow.
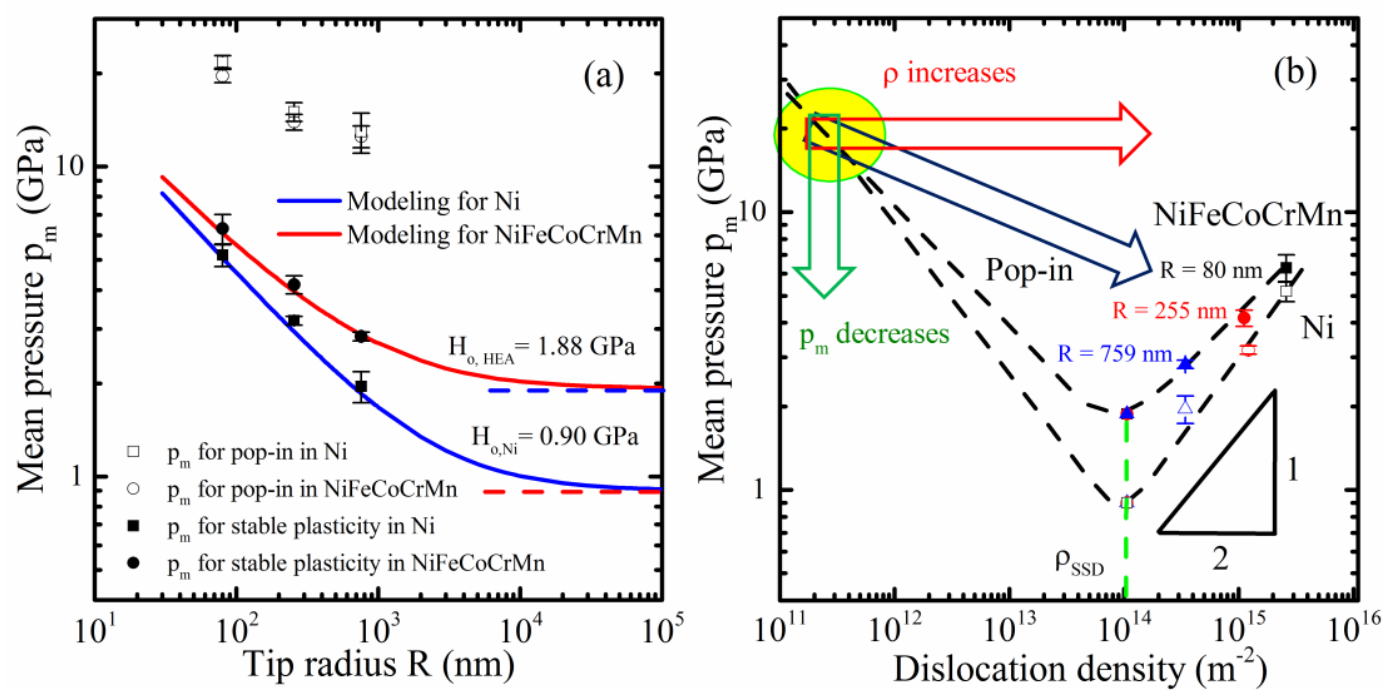

Figure 8 Mean pressure $\mathrm{p}_{\mathrm{m}}$ underneath the indenters as a function of tip radius (a) and dislocation density (b) in NiFeCoCrMn and Ni single crystal. Solid lines in (a) are theoretical predictions of $\mathrm{p}_{\mathrm{m}}$ for global plasticity based on Eq. (11).

Mean pressures for the first pop-in (open symbols) and after the pop-in (solid symbols) are noted to decrease with increasing tip radius $R$ in Figure 8a. However, the decreasing trends for data before and after the pop-in are caused by different mechanisms. For the onset of yielding, i.e., the start of very first pop-in, the drop of critical stress results from the activation of preexisting dislocations in the highly stressed zone and it is more likely to encounter pre-existing dislocations beneath an indenter with a larger tip radius. On the other hand, after finishing the pop-in and in the plastic region, the flow stress is determined by the dislocation density, which is given by $\rho_{S S D}+1 / f^{3} b R$. A larger tip radius $R$ would lower the density of geometrically necessary dislocation, thus reduces $p_{m}$ (or the flow stress). The fact that higher plastic flow stress is obtained in NiFeCoCrMn suggests this HEA has a stronger lattice friction or dislocation 
interaction. The decreasing trend of mean pressure $p_{\mathrm{m}}$ with the tip radius in the plastic region can be predicted by the equation

$$
p_{m}=\Delta H+C M \alpha G b \sqrt{\rho_{S S D}+1 / f^{3} b R}
$$

Inserting proper parameters, predicted values of mean pressure in Eq. (11) are found to agree well with the experimental results, as shown in Figure 8. As the tip radius increases, the size effect weakens and $p_{\mathrm{m}}$ converges to $H_{\mathrm{o}}$ at very large indentation depth.

The data of $\mathrm{p}_{\mathrm{m}}$ are replotted against dislocation density and form a "U-shape" curve, as shown in Figure 8b. Similar schematic diagrams illustrating indentation plasticity have been presented by Zhang et al [52] and Lilleodden et al [55]. In the figure, the statistically stored dislocation density $\rho_{\mathrm{SSD}}=1.065 \times 10^{14} \mathrm{~m}^{-2}$ obtained from the ISE analysis is located at the bottom of the U-curve. It represents the minimum dislocation density required to sustain continuum plasticity in the fcc-structure materials. In the current fully annealed HEA and $\mathrm{Ni}$ materials, the dislocation density $\rho\left(10^{11} \mathrm{~m}^{-2}\right)$ is much lower than the critical value $\left(10^{14} \mathrm{~m}^{-2}\right)$, plasticity can only be triggered in the form of pop-in under high $\mathrm{p}_{\mathrm{m}}$. The pop-in causes an abrupt increase in $\rho$ and, meanwhile, a sudden increase in contact area, thus a rapid decrease in $\mathrm{p}_{\mathrm{m}}$ underneath the indenter. Both $\mathrm{p}_{\mathrm{m}}$ and $\rho$ are tip radius-dependent, and a power-law correlation between them is revealed in Figure $8 \mathrm{~b}$. The power index is about 0.5 , which is apparently resulted from the Taylor hardening.

\section{Conclusions}


We have studied the elastic and plastic deformations of a high entropy alloy $\mathrm{NiFeCoCrMn}$ using instrumented indentation techniques and directly compared the results with those of a single-crystal Ni. The effect of indentation tip radius on the deformation processes has also been evaluated and discussed. Several conclusions are drawn as follows.

1. Incipient plasticity revealed as indentation pop-in is generally observed in both $\mathrm{NiFeCoCrMn}$ and the Ni single crystal. The critical shear stresses required for the occurrence of pop-in are within the range of the theoretical strength of each material. The activation volumes for dislocation nucleation in NiFeCoCrMn $\left(0.65 \mathrm{~b}^{3}\right)$ and $\mathrm{Ni}\left(0.69 \mathrm{~b}^{3}\right)$ are quite similar.

2. The pop-in stress decreases with increasing tip radius in both $\mathrm{NiFeCoCrMn}$ and Ni. This is attributable to the fact that a larger indented volume is expected to have a higher probability to contain pre-existing dislocations. A model combining dislocation nucleation in a dislocation-free crystal and dislocation activation in a crystal consisting of pre-existing dislocations is proposed, and it describes well the cumulative pop-in probability in both materials.

3. Indentation results in the plastic region indicate that $\mathrm{NiFeCoCrMn}$ is stronger than $\mathrm{Ni}$. A strengthening effect $(\Delta H=0.98 \mathrm{GPa})$ in the HEA is universally observed in the full range of indentation, and it agrees with the results obtained in the conventional tensile tests.

4. Indentation size effect is observed in both $\mathrm{NiFeCoCrMn}$ and $\mathrm{Ni}$. The load-displacement responses under higher load (or larger indentation depth) can be described by the Nix-Gao model, whereas a modified Swadener's model for spherical indenter offers a better description in the case of shallow depth. In either case, a scaling factor $f$ is necessarily introduced to describe the effective size of plastic zone underneath the indenter, and it ranges from 2.4 to 2.65 for $\mathrm{NiFeCoCrMn}$ and $\mathrm{Ni}$. 


\section{Acknowledgements}

This work (DW and TGN) was performed under the NSF Contract DMR-1408722. JSCJ is supported by MOST103-2221-E-008-028-MY3, ROC. We appreciate the technical discussion with Professor Zhaoping Lu in University of Science and Technology-Beijing. We are also grateful to Dr. H. Bei for the preparation of Ni single crystal in Oak Ridge National Laboratory. Dr. Maulik Patel is acknowledged for his help in collecting the XRD data using the instruments that were procured through the general infrastructure grant of DOE-Nuclear Energy University Program (DE-NE0000693). 


\section{Reference}

[1] Tsai M-H, Yeh J-W. High-Entropy Alloys: A Critical Review. Mater Res Lett 2014;2:107-23. doi:10.1080/21663831.2014.912690.

[2] Yeh J-W, Chen S-K, Lin S-J, Gan J-Y, Chin T-S, Shun T-T, et al. Nanostructured High-Entropy Alloys with Multiple Principal Elements: Novel Alloy Design Concepts and Outcomes. Adv Eng Mater 2004;6:299-303. doi:10.1002/adem.200300567.

[3] Manzoni a., Daoud H, Mondal S, Van Smaalen S, Völkl R, Glatzel U, et al. Investigation of phases in $\mathrm{A} 123 \mathrm{Co} 15 \mathrm{Cr} 23 \mathrm{Cu} 8 \mathrm{Fe} 15 \mathrm{Ni16}$ and $\mathrm{Al}$ 8Co17Cr17Cu8Fe17Ni 33 high entropy alloys and comparison with equilibrium phases predicted by Thermo-Calc. J Alloys Compd 2013;552:430-6. doi:10.1016/j.jallcom.2012.11.074.

[4] Manzoni a., Daoud H, Völkl R, Glatzel U, Wanderka N. Phase separation in equiatomic AlCoCrFeNi high-entropy alloy. Ultramicroscopy 2013;132:212-5. doi:10.1016/j.ultramic.2012.12.015.

[5] Ng C, Guo S, Luan J, Shi S, Liu CT. Entropy-driven phase stability and slow diffusion kinetics in an $\mathrm{Al}$ 0.5CoCrCuFeNi high entropy alloy. Intermetallics 2012;31:165-72. doi:10.1016/j.intermet.2012.07.001.

[6] Pradeep KG, Wanderka N, Choi P, Banhart J, Murty BS, Raabe D. Atomic-scale compositional characterization of a nanocrystalline $\mathrm{AlCrCuFeNiZn} \mathrm{high-entropy} \mathrm{alloy} \mathrm{using} \mathrm{atom} \mathrm{probe}$ tomography. Acta Mater 2013;61:4696-706. doi:10.1016/j.actamat.2013.04.059.

[7] Singh S, Wanderka N, Murty BS, Glatzel U, Banhart J. Decomposition in multi-component AlCoCrCuFeNi high-entropy alloy. Acta Mater 2011;59:182-90. doi:10.1016/j.actamat.2010.09.023.

[8] Singh S, Wanderka N, Kiefer K, Siemensmeyer K, Banhart J. Effect of decomposition of the Cr$\mathrm{Fe}-\mathrm{Co}$ rich phase of $\mathrm{AlCoCrCuFeNi}$ high entropy alloy on magnetic properties. Ultramicroscopy 2011;111:619-22. doi:10.1016/j.ultramic.2010.12.001.

[9] Liu L, Zhu JB, Zhang C, Li JC, Jiang Q. Microstructure and the properties of FeCoCuNiSnx high entropy alloys. Mater Sci Eng A 2012;548:64-8. doi:10.1016/j.msea.2012.03.080.

[10] Tang Z, Gao MC, Diao H, Yang T, Liu J, Zuo T, et al. Aluminum alloying effects on lattice types, microstructures, and mechanical behavior of high-entropy alloys systems. Jom 2013;65:1848-58. doi:10.1007/s11837-013-0776-z.

[11] Wang XF, Zhang Y, Qiao Y, Chen GL. Novel microstructure and properties of multicomponent CoCrCuFeNiTix alloys. Intermetallics 2007;15:357-62. doi:10.1016/j.intermet.2006.08.005. 
[12] Zhu JM, Fu HM, Zhang HF, Wang a. M, Li H, Hu ZQ. Microstructures and compressive properties of multicomponent AlCoCrFeNiMox alloys. Mater Sci Eng A 2010;527:6975-9. doi:10.1016/j.msea.2010.07.028.

[13] Cantor B, Chang ITH, Knight P, Vincent a. JB. Microstructural development in equiatomic multicomponent alloys. Mater Sci Eng A 2004;375-377:213-8. doi:10.1016/j.msea.2003.10.257.

[14] Yao MJ, Pradeep KG, Tasan CC, Raabe D. A novel, single phase, non-equiatomic FeMnNiCoCr high-entropy alloy with exceptional phase stability and tensile ductility. Scr Mater 2014;72-73:5-8. doi:10.1016/j.scriptamat.2013.09.030.

[15] Zou Y, Maiti S, Steurer W, Spolenak R. Size-dependent plasticity in an Nb25Mo25Ta 25W25 refractory high-entropy alloy. Acta Mater 2014;65:85-97. doi:10.1016/j.actamat.2013.11.049.

[16] Senkov ON, Scott JM, Senkova S V., Miracle DB, Woodward CF. Microstructure and room temperature properties of a high-entropy TaNbHfZrTi alloy. J Alloys Compd 2011;509:6043-8. doi:10.1016/j.jallcom.2011.02.171.

[17] Senkov ON, Wilks GB, Miracle DB, Chuang CP, Liaw PK. Refractory high-entropy alloys. Intermetallics 2010;18:1758-65. doi:10.1016/j.intermet.2010.05.014.

[18] Chen SY, Yang X, Dahmen K a., Liaw PK, Zhang Y. Microstructures and crackling noise of AlxNbTiMoV high entropy alloys. Entropy 2014;16:870-84. doi:10.3390/e16020870.

[19] Takeuchi A, Amiya K, Wada T, Yubuta K, Zhang W. High-Entropy Alloys with a Hexagonal Close-Packed Structure Designed by Equi-Atomic Alloy Strategy and Binary Phase Diagrams. Jom 2014;66:1984-92. doi:10.1007/s11837-014-1085-x.

[20] He JY, Liu WH, Wang H, Wu Y, Liu XJ, Nieh TG, et al. Effects of Al addition on structural evolution and tensile properties of the FeCoNiCrMn high-entropy alloy system. Acta Mater 2014;62:105-13. doi:10.1016/j.actamat.2013.09.037.

[21] He JY, Zhu C, Zhou DQ, Liu WH, Nieh TG, Lu ZP. Steady state flow of the FeCoNiCrMn high entropy alloy at elevated temperatures. Intermetallics 2014;55:9-14.

doi:10.1016/j.intermet.2014.06.015.

[22] Liu WH, Wu Y, He JY, Nieh TG, Lu ZP. Grain growth and the Hall-Petch relationship in a highentropy FeCrNiCoMn alloy. Scr Mater 2013;68:526-9. doi:10.1016/j.scriptamat.2012.12.002.

[23] Otto F, Dlouhý a., Somsen C, Bei H, Eggeler G, George EP. The influences of temperature and microstructure on the tensile properties of a CoCrFeMnNi high-entropy alloy. Acta Mater 2013;61:5743-55. doi:10.1016/j.actamat.2013.06.018.

[24] Otto F, Hanold NL, George EP. Microstructural evolution after thermomechanical processing in an equiatomic, single-phase $\mathrm{CoCrFeMnNi}$ high-entropy alloy with special focus on twin boundaries. Intermetallics 2014;54:39-48. doi:10.1016/j.intermet.2014.05.014. 
[25] Stepanov N, Tikhonovsky M, Yurchenko N, Zyabkin D, Klimova M, Zherebtsov S, et al. Effect of cryo-deformation on structure and properties of CoCrFeNiMn high-entropy alloy. Intermetallics 2015;59:8-17. doi:10.1016/j.intermet.2014.12.004.

[26] Zhu C, Lu Z, Nieh T. Incipient plasticity and dislocation nucleation of FeCoCrNiMn high-entropy alloy. Acta Mater 2013;61:2993-3001. doi:http://dx.doi.org/10.1016/j.actamat.2013.01.059.

[27] Wu Z, Bei H, Otto F, Pharr GM, George EP. Recovery, recrystallization, grain growth and phase stability of a family of FCC-structured multi-component equiatomic solid solution alloys. Intermetallics 2014;46:131-40. doi:10.1016/j.intermet.2013.10.024.

[28] Wu Z, Bei H, Pharr GM, George EP. Temperature dependence of the mechanical properties of equiatomic solid solution alloys with face-centered cubic crystal structures. Acta Mater 2014;81:428-41. doi:10.1016/j.actamat.2014.08.026.

[29] Wu D, Morris JR, Nieh TG. Effect of tip radius on the incipient plasticity of chromium studied by nanoindentation. Scr Mater 2015;94:52-5. doi:10.1016/j.scriptamat.2014.09.017.

[30] Morris JR, Bei H, Pharr GM, George EP. Size Effects and Stochastic Behavior of Nanoindentation Pop In. Phys Rev Lett 2011;106:165502.

[31] Shim S, Bei H, George EP, Pharr GM. A different type of indentation size effect. Scr Mater 2008;59:1095-8. doi:DOI: 10.1016/j.scriptamat.2008.07.026.

[32] Simmons G, Wang H. Single Crystal Elastic Constants and Calculated Aggregate Properties. 2nd editio. Cambridge: The MIT Press; 1971.

[33] McElhaney KW, Vlassak JJ, Nix WD. Determination of indenter tip geometry and indentation contact area for depth-sensing indentation experiments. J Mater Res 1998;13:1300-6. doi:10.1557/JMR.1998.0185.

[34] Ma Q, Clarke DR. Size dependent hardness of silver single crystals. J Mater Res 1995;10:853-63. doi:10.1557/JMR.1995.0853.

[35] Nix WD, Gao HJ. Indentation size effects in crystalline materials: A law for strain gradient plasticity. J Mech Phys Solids 1998;46:411-25.

[36] Feng G, Nix WD. Indentation size effect in MgO. Scr Mater 2004;51:599-603. doi:10.1016/j.scriptamat.2004.05.034.

[37] Yee Lim, M M Chaudhri Y. The effect of the indenter load on the nanohardness of ductile metals: an experimental study on polycrystalline work-hardened and annealed oxygen-free copper. Philos Mag A 1999;79:2979-3000. doi:10.1080/014186199251193.

[38] Huang Y, Zhang F, Hwang K, Nix W, Pharr G, Feng G. A model of size effects in nanoindentation. J Mech Phys Solids 2006;54:1668-86. doi:10.1016/j.jmps.2006.02.002. 
[39] Kamimura Y, Edagawa K, Takeuchi S. Experimental evaluation of the Peierls stresses in a variety of crystals and their relation to the crystal structure. Acta Mater 2013;61:294-309.

doi:10.1016/j.actamat.2012.09.059.

[40] Barnoush A, Welsch MT, Vehoff H. Correlation between dislocation density and pop-in phenomena in aluminum studied by nanoindentation and electron channeling contrast imaging. Scr Mater 2010;63:465-8. doi:10.1016/j.scriptamat.2010.04.048.

[41] Guo W, Dmowski W, Noh J-Y, Rack P, Liaw PK, Egami T. Local Atomic Structure of a HighEntropy Alloy: An X-Ray and Neutron Scattering Study. Metall Mater Trans A 2012;44:1994-7. doi:10.1007/s11661-012-1474-0.

[42] Durst K, Backes B, Franke O, Göken M. Indentation size effect in metallic materials: Modeling strength from pop-in to macroscopic hardness using geometrically necessary dislocations. Acta Mater 2006;54:2547-55. doi:http://dx.doi.org/10.1016/j.actamat.2006.01.036.

[43] Durst K, Backes B, Göken M. Indentation size effect in metallic materials: Correcting for the size of the plastic zone. Scr Mater 2005;52:1093-7. doi:10.1016/j.scriptamat.2005.02.009.

[44] Schuh CA, Lund AC. Application of nucleation theory to the rate dependence of incipient plasticity during nanoindentation. J Mater Res 2004;19:2152-8. doi:10.1557/JMR.2004.0276.

[45] Li TL, Bei H, Morris JR, George EP, Gao YF. Scale effects in convoluted thermal/spatial statistics of plasticity initiation in small stressed volumes during nanoindentation. Mater Sci Technol 2012;28:1055-9. doi:10.1179/1743284712Y.0000000007.

[46] Mason JK, Lund AC, Schuh CA. Determining the activation energy and volume for the onset of plasticity during nanoindentation. Phys Rev B 2006;73:54102.

[47] Bell JF. Generalized large deformation behavior for face-centered cubic solids - nickel aluminum gold silver and lead. Philos Mag 1965;11:1135-56. doi:10.1080/14786436508224924.

[48] Wu D, Zhang J, Huang JC, Bei H, Nieh TG. Grain-boundary strengthening in nanocrystalline chromium and the Hall-Petch coefficient of body-centered cubic metals. Scr Mater 2013;68:11821. doi:http://dx.doi.org/10.1016/j.scriptamat.2012.09.025.

[49] Norfleet DM, Dimiduk DM, Polasik SJ, Uchic MD, Mills MJ. Dislocation structures and their relationship to strength in deformed nickel microcrystals. Acta Mater 2008;56:2988-3001. doi:10.1016/j.actamat.2008.02.046.

[50] Wu D, Nieh TG. Incipient plasticity and dislocation nucleation in body-centered cubic chromium. Mater Sci Eng A 2014;609:110-5. doi:10.1016/j.msea.2014.04.107.

[51] Swadener J, George E, Pharr G. The correlation of the indentation size effect measured with indenters of various shapes. J Mech Phys Solids 2002;50:681-94.

[52] Zhang L, Ohmura T. Plasticity Initiation and Evolution during Nanoindentation of an Iron-3\% Silicon Crystal. Phys Rev Lett 2014;112:145504. doi:10.1103/PhysRevLett.112.145504. 
[53] Durst K, Göken M, Pharr GM. Indentation size effect in spherical and pyramidal indentations. J Phys D Appl Phys 2008;41:074005. doi:10.1088/0022-3727/41/7/074005.

[54] Cordill MJ, Moody NR, Gerberich WW. The role of dislocation walls for nanoindentation to shallow depths. Int J Plast 2009;25:281-301. doi:10.1016/j.ijplas.2008.02.003.

[55] Lilleodden ET, Nix WD. Microstructural length-scale effects in the nanoindentation behavior of thin gold films. Acta Mater 2006;54:1583-93. doi:http://dx.doi.org/10.1016/j.actamat.2005.11.025. 


\section{Graphical Abstract}

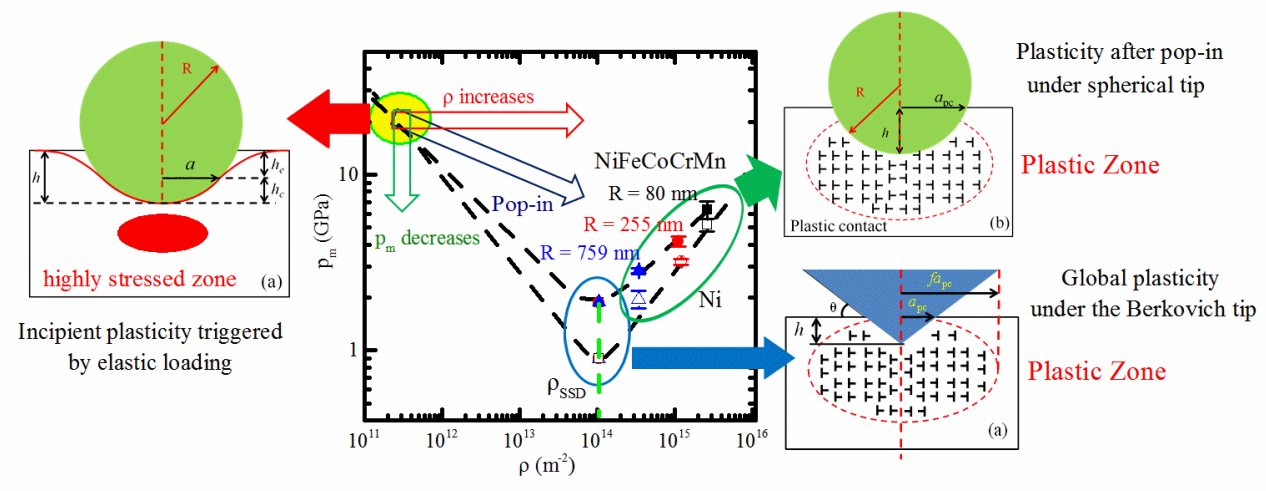

